\title{
A docência numa universidade em mudança
}

\author{
Carlos Osmar Bertero*
}

\section{Resumo}

0 pano de fundo do artigo são as transformações da universidade. De uma instituição para poucos e com qualidade possivelmente superior, passa a ser uma universidade para a massa. 0 ideal de alfabetização universal agora é deslocado para a educação superior. No país, criou-se uma lacuna não só numérica, mas qualitativa entre a pós- graduação stricto sensu e a graduação que abriga seis centenas de milhares de matrículas. A lacuna é explorada e, ao final, é sugerido o que pode ser feito para reduzi-la, apresentando-se o esforço da Associação Nacional de Pesquisa e Pós-Graduação em Administração (Anpad), através de seu Programa de Capacitação de Docentes em Administração (PCDA), que busca sensibilizar os programas de pós graduação, voltados predominantemente para pesquisar e publicar, para que também incluam na formação de mestres e doutores a dimensão docente.

Palavras-chave: graduação; pós graduação; treinamento; professores.

\begin{abstract}
Changes have been taking place in Brazilian higher education. The ideal of universal literacy was extended and the expectation is that everyone has access to college education. In Brazil a gap developed between graduate and undergraduate education where the first being necessarily smaller enjoys higher quality. Undergraduate courses show a registration of more than six hundred thousand students. The gap and its reasons are explored and suggestions are advanced for filling it. The article ends with a presentation of the efforts of ANPAD- The Brazilian Academy of Management through its programs for Faculty Training in Administration and Management to make graduate programs more sensitive to teaching needs without loosing the existing focus on research and publications.
\end{abstract}

Key words: education graduate; education undergraduate; faculty training; faculty development.

\section{Introdução}

A pós-graduação brasileira, por suas origens e pelo modelo adotado, afirmou a indissolubilidade entre ensino e pesquisa. O modelo, que nos chegou através da reforma universitária e de decisões do antigo Conselho Federal de Educação (CFE), ainda em meados da década de 1960, adotava o modelo alemão com a mediação do modelo universitário norte-americano. O modelo originado na Universidade de Berlim em princípios do século XIX e adotado pela universidade norte americana, centralizava as atividades de pós-graduação numa graduate school e tornava os graus de mestre e doutor (especialmente esse último) um treinamento para a realização da pesquisa. Embora se entendesse que os doutores seriam também docentes, afirmava-se que a boa docência estaria necessariamente baseada na pesquisa. Sintetizando: só se ensina o que se pesquisa. O ensino deve ser a transmissão aos demais dos resultados da pesquisa e, portanto, do avanço do conhecimento.

O modelo sobrevive até hoje e é bastante fecundo. Entretanto, deve-se fazer um reparo e contextualizar a questão. Ele é adequado, mesmo nos EUA - país onde primeiro a educação superior se massificou -, apenas, para um reduzido número de universidades, exatamente, aquelas que produzem conhecimento e são consideradas centros de excelência. Naquele país, a maior parte (aproximadamente $70 \%$ da produção científica)

\footnotetext{
Ph.D. in Business Administration - Cornell University. Professor Titular do Departamento de Administração Geral e Recursos Humanos da FGV/EAESP. Endereço: Av. 9 de Julho, 2029 - Bela Vista - 01313- 902 - São Paulo - SP. E- mail: cbertero@ fgvsp.br.

* Artigo recebido em outubro de 2006 e aceito para publicação em dezembro de 2006.
} 
está concentrada em cerca de 100 universidades. As demais não são centros geradores de conhecimento, mas transmissores de conhecimento, pois sua principal atividade é de fato o ensino e não a pesquisa.

O ensino como resultado da pesquisa e o fato de um doutor ensinar apenas o que pesquisasse são características compatíveis com um modelo de universidade que hoje está restrito a nichos, ainda que de inegável importância. No entanto, esses nichos não constituem o mundo da universidade massificada. Quando a pós-graduação foi concebida, ela também tinha a vocação de zelar pela reprodução no tempo da instituição universitária, formando os professores e pesquisadores necessários à consecução das tarefas de manutenção institucional. $\mathrm{O}$ acesso à universidade era restrito. Mesmo nos países mais avançados econômica e socialmente poucos tinham acesso à universidade. Na maioria dos países europeus, as universidades mantiveram até bem pouco as características de organizações relativamente elitizadas onde o alunado provinha dos estratos sociais mais elevados e representavam pequena percentagem da população em idade de freqüentar a universidade. As reformas e transformações pelas quais passaram as universidades inglesas e francesas a partir das décadas de 1960 e 1970 foram no sentido de franqueá-las a segmentos da população até então afastados do mundo universitário.

No Brasil, essas transformações também se iniciaram na década de 1960, mas o passo da mudança foi bem mais lento. De aproximadamente 100.000 matrículas em 1960, quando nossa população era de 70 milhões para os 4.400.000 atuais numa população de aproximadamente 180 milhões, percebemos um salto em termos absolutos do número de matrículas, mas certamente permanecemos muito distantes do ideal de matricular na universidade uma parcela substantiva da faixa etária que lá deveria estar. Atualmente, apenas aproximadamente $13 \%$ dos brasileiros na faixa etária respectiva estão matriculados em cursos superiores.

Em síntese, a universidade mudou muito e a pós-graduação ainda permanece fiel a um modelo desenvolvido para uma universidade e uma sociedade de quase dois séculos atrás. A questão é saber até que ponto esse modelo deve ser mantido. Não há dúvida que a pós-graduação corresponde a um modelo de busca de excelência. Mesmo com a sua expansão, como aconteceu em diversos países, especialmente nos EUA, isso não eliminou uma nítida estratificação. Há milhares de programas de mestrado e doutorado, mas a produção científica, a geração de conhecimento e a excelência reconhecida estão em número que não vai além de algumas dezenas. Poder-se-ia levantar a espinhosa questão de saber se o talento e a excelência são massificáveis.

Em nosso país, desde o início foi determinado que a pós-graduação influenciaria a graduação, fecundando-a e aprimorando-a. Buscou-se evitar o seu enquistamento na estrutura da universidade. A pós-graduação é parte do departamento. Além do mais, a universidade brasileira nunca chegou a ter uma graduate school nos moldes americanos, a qual se ocupava da pós-graduação sobrepondo-se aos diversos colleges. Mesmo nossas próreitorias de pós-graduação e pesquisa, quando existem, não possuem as atribuições de uma graduate school. Ainda recomenda-se que os professores da pós-graduação não se afastem do ensino na graduação e a avaliação dos programas pela Capes pontua a docência de professores da pós-graduação na graduação.

Contudo, apesar de todas essas recomendações e cautelas formais, criou-se e aparentemente aumentou a lacuna entre a pós-graduação e a graduação. A massificação dos cursos de graduação não correspondeu à manutenção ou ao aprimoramento de sua qualidade. Atualmente, as preocupações da própria área - como se pode registrar nas reuniões e trabalhos apresentados nos Encontros da Associação Nacional de Cursos de Graduação em Administração (Enangrads) - prestigiam as questões relativas à melhoria da qualidade dos cursos de graduação. Trata-se do maior número de matrículas, hoje, com $15 \%$ do total, fragmentadas em mais de 2.000 cursos de graduação, onde se admite que a maioria carece de níveis considerados minimamente satisfatórios.

A pós-graduação também se expandiu a partir de meados da década de 1990, mas a um ritmo incrivelmente menor. Atualmente, registram-se no máximo 80 programas, incluindo mestrados acadêmicos, profissionais e doutorados. Entretanto, cabe perguntar até que ponto os programas de pós-graduação stricto sensu se preocupam com aprimorar a qualidade dos cursos de graduação. A resposta pode ser encontrada na maneira como esses programas são operados e no que consistem as tarefas de docentes e discentes. 
$\mathrm{Na}$ verdade, embora se diga que o ensino não deva estar afastado da pós-graduação, ela acaba por prestigiar muito mais a pesquisa e as publicações do que o ensino. Isso está em boa medida vinculado aos critérios pelos quais se avaliam cursos de pós-graduação e também à maneira como se estrutura a carreira docente nas principais universidades do país. Naturalmente não se trata de uma criação exclusivamente nacional. Foi também adotada com base nas experiências e na realidade de carreiras docentes noutros países, especialmente do Atlântico norte. O professor e os programas são avaliados em função do que publicam. Bons programas devem conter não só substancial produção científica de docentes, mas também de alunos. Isso sinaliza que alunos de mestrado e doutorado devem publicar já durante o período em que estão cursando créditos, pesquisando e redigindo suas teses e dissertações.

Nessas condições, ensinar pode ser visto (e freqüentemente o é) como uma perda de foco, um tempo não muito bem alocado que acaba por prejudicar a pesquisa e a publicação. $O$ ensino na graduação é visto como fardo problemático de ser carregado. Os níveis sofríveis do alunado e as condições em que a docência é exercida, na maioria desses programas, acaba por torná-los quase um ônus a ser carregado por falta de alternativa ou para satisfação de algumas exigências do próprio processo de avaliação, que demanda também inserção de docentes da pós-graduação na graduação. O entusiasmo pela docência na graduação não é difundido entre alunos e professores de cursos stricto sensu.

\section{Tranforformações no ensino de graduação}

No Brasil, a pressão por aumento de vagas na graduação iniciou-se após o término da II Guerra Mundial, quando a industrialização e a urbanização se aceleraram. Outro componente dessas transformações foi a expansão de uma classe média urbana, principal demandante por vagas na universidade. Até então, a universidade brasileira era quase exclusivamente pública, com algumas poucas instituições confessionais. O Estado brasileiro reagiu de maneira dúbia a essas demandas. Depois de uma vigorosa expansão do sistema universitário federal entre 1950 e a década de 1970, a opção foi pela privatização, reservando-se ao poder público a regulamentação, fiscalização e controle do sistema através do Ministério da Educação e do Conselho Federal de Educação, posteriormente, substituído pelo Conselho Nacional de Educação (CNE). O resultado foi o perfil predominantemente privado de nosso ensino superior, onde cerca de $3 / 4$ das vagas estão em IESInstituições de Ensino Superior privadas.

A privatização num país com renda altamente concentrada como é o nosso, acaba por ter implicações sérias para a expansão do ensino superior. As escolas vivem de taxas ou anuidades escolares. O número de vagas quase sempre supera, na área de administração, o número de candidatos inscritos nos vestibulares. Isso faz com que a lista de inscritos seja a lista de matrículas. Todavia, é necessário pagar e, aqui, o gargalo da renda se manifesta. As classes alta e média alta são tradicionais clientes da universidade brasileira, e até recentemente os únicos a freqüentá-la. A frente de expansão para a desejada inclusão dos brasileiros na educação universitária tem como alvo, hoje, a classe média baixa e mesmo a classe baixa. No entanto, o nível de renda desses estratos sociais fazem com que as perspectivas não sejam nada auspiciosas quanto às suas possibilidades de acesso ao sistema privado de ensino.

A universidade mudou e continua mudando no Brasil e pelo mundo a fora. Talvez, o próprio termo universidade no singular seja um exagero. Mais apropriado seria falar de universidades, porque em épocas passadas ela não apresentava um perfil homogêneo. Havia universidades propensas à massificação e à aproximação com as necessidades do mercado, como foi o caso da universidade francesa com as reformas napoleônicas. Havia universidades propositadamente distanciadas do mercado e mais voltadas a uma busca de conhecimentos, mesmo que estes não acenassem com aplicações práticas, como foi o caso da universidade alemã. Havia ainda a universidade inglesa, presa a um modelo de ensino calcado na erudição e que também não se curvava às necessidades do mercado, embora preparasse quadros da aristocracia inglesa para o exercício das mais diversas profissões. Finalmente, tivemos a universidade norte-americana, marcada igualmente por grande heterogeneidade e diversidade de objetivos. Havia as clássicas e tradicionais, remontando ainda ao período colonial e que nasceram influenciadas pelo modelo britânico e também voltadas para a formação de clérigos para as igrejas reformadas. Além disso, surgiu em meados do século XIX uma universidade ligada às 
necessidades do mercado e voltada ao desenvolvimento regional. Foi o caso dos land grant colleges, que deram origem a muitas das atuais universidades estaduais norte americanas (state universities), mas que começaram voltadas principalmente para o atendimento das necessidades do setor primário, com ênfase em agronomia, medicina veterinária e nas diversas engenharias.

Essas origens são aqui registradas a fim de que se possa perceber o quanto a universidade vem se transformando, independentemente do país em que esteja localizada. Traços das origens certamente são encontrados, mas a realidade atual é bem diversa daquilo que se encontrava nessas universidades há apenas algumas décadas. Dessas mudanças, aqui realçamos a massificação ou a abertura da universidade, em princípio, a todos. O ideal de educação universal é recente. Ele surgiu apenas como um dos resultados da Revolução Francesa. A alfabetização universal começou a ser perseguida pelos países da Europa Ocidental ainda no século XIX, mas só atingiu plenamente seus objetivos na primeira metade do século XX. Da Europa, a proposta de que todo cidadão tinha direito à educação básica ou fundamental se universalizou. Atualmente, é buscada por todos os países que ainda não a obtiveram, o que significa todo o Terceiro Mundo.

Assistimos hoje a uma nova etapa nesse processo de universalização da educação, quando a proposta é oferecer a oportunidade de educação superior a todos os cidadãos. Poucos países já o conseguiram. Talvez os países nórdicos sejam aqueles onde a maior percentagem da população na faixa etária respectiva esteja matriculada na universidade e onde o percentual da população que se diplomou na universidade gire em torno de $2 / 3$ da população. Nos países do Terceiro Mundo esse percentual ainda é ínfimo. Se compararmos os contingentes populacionais nórdicos com aqueles existentes em boa parte dos países de Terceiro Mundo, incluído o Brasil, conclui-se que é uma tarefa hercúlea. É exatamente nesse contexto que devemos contemplar os problemas de docência e de apoio ao ensino por parte da pós-graduação em nossa área de administração.

Em nosso país, a área de administração nos coloca em meio a uma situação de massificação, implicando mudanças nos objetivos da universidade, no perfil do alunado e conseqüentemente nas competências exigidas do professor. $\mathrm{O}$ aluno que hoje se encontra nas salas de aula é muito diferente do que era encontrado há não muito tempo. Mesmo professores jovens que começam a lecionar cinco ou 10 anos após a conclusão de seu curso de graduação experimentam o chamado "choque de gerações", que se reflete nas atitudes, expectativas e na maneira de entender a universidade e um curso superior.

É fundamental que se entenda que a grande dificuldade atual será tentar "educar" os alunos. Aqui se entende educação como informá-los sobre uma série de questões relativas à aquisição de um senso crítico, conhecimentos sobre assuntos que não sejam percebidos como tendo repercussões imediatas em suas vidas. Se quisermos ver o tamanho da lacuna, tomemos o exemplo de um guru administrativo recentemente falecido. A referência é a Peter Drucker. Austríaco de nascimento, fez em Viena um curso de graduação em economia. Não era mestre nem doutor, mas possivelmente era e se considerava uma pessoa educada. Sua formação envolvia estudos clássicos, como grego e latim, conhecimento de disciplinas fundamentais como matemática, as diversas ciências e filosofia, além de teoria e história econômica. Havia uma carga pesada em humanidades, sem que isso implicasse minorar o peso das chamadas áreas exatas. Isso tudo aconteceu há menos de um século. Na verdade, Drucker nasceu em 1908 e chegou aos bancos da universidade por volta de 1926. Se quisermos uma comparação com uma geração mais recente, bastaria tomar alguém que tenha cursado a graduação na década de 1970, há apenas 30 anos, e as diferenças já são notórias.

\section{0 perfil dos novos alunos}

Até recentemente, educar implicava cultivar, polir, esmerar as pessoas que se educavam. Deveria desenvolverse uma base sólida de conhecimentos e ainda um mínimo de domínio do gosto e capacitação crítica. Todas essas características do educar estavam ligadas, como é inevitável, a uma sociedade de classes, onde se entendia que educar era adquirir as habilidades das classes mais altas. A massa composta por mais de 600.000 alunos atualmente matriculados em nossos cursos de graduação em administração constitui matéria prima muito remotamente adequada para ser educada segundo esses critérios até recentemente predominantes. Ela é distinta da clientela tradicional da universidade brasileira que até poucas décadas era a única a ter acesso a cursos superiores. 
Alguns dos traços encontrados em nossos alunos de graduação são relacionados a seguir:

- boa parte vem de famílias onde são os primeiros a cursar uma universidade. Portanto, não existe o chamado background educacional e cultural que possa ter facilitado as coisas e já prepará-los para os bancos universitários;

- os vínculos que ligam o atual alunado à universidade são bem diversos dos que existiam em gerações passadas. Seu interesse em educação, como entendida até recentemente e ainda hoje partilhada por muitos educadores, não chega a sensibilizá-lo;

- trata-se não propriamente de um estudante universitário, como a maioria dos brasileiros que freqüentaram cursos superiores há uma ou duas gerações. $\mathrm{O}$ aluno atual é mais um trabalhador que vai às aulas do que propriamente um estudante. Ele entende que estudar é estar presente na sala de aula. O que tiver que ser apreendido o será naquelas horas alocadas em sua apertada agenda;

- o que busca na universidade não é a educação, com implicações de formação, mas um treinamento rápido que lhe permita melhorar suas chances de ascensão e, mesmo, de simples emprego na estrutura ocupacional existente.

O perfil do nosso estudante de graduação em administração poderia ser descrito em termos de média, mediana ou moda como:

- dividido ao meio em termos de gênero, com ligeira predominância das mulheres, que são já maioria entre os matriculados;

- tem entre 18 e 26 anos de idade, salvo alguns outliers, que tem aumentado e que são mais velhos;

- são pessoas que deixaram a escola após concluírem o ensino médio, mas que decidem voltar aos bancos escolares, prestando vestibular ao redor dos 30 anos ou até mesmo um pouco depois. Nossos alunos são oriundos predominantemente de um sistema público de ensino fundamental e médio;

- é parte de uma família de cinco membros com renda mensal que o posiciona na classe média baixa. O pagamento das taxas escolares é um sacrifício familiar. Mesmo quando o estudante paga as taxas escolares com seu próprio salário, isto faz com que a família tenha que abdicar temporariamente de sua contribuição para o orçamento familiar;

- estuda em período noturno, dedicando a maior parte de seu tempo a um trabalho em regime de tempo integral que pode obrigá-lo a trabalhar mais do que as oito horas legalmente estabelecidas, sem que haja possibilidade de recusa para as " horas extras";

- estuda numa Instituição de Ensino Superior privada, pois mais de $80 \%$ das vagas em administração estão em escolas privadas. A instituição de ensino onde estuda não dispõe de programas de auxílio a alunos carentes;

- ocupa posição ainda modesta na estrutura ocupacional do país, com remuneração correspondente. Em termos de média nacional pode-se afirmar que o salário mensal não chega a $\mathrm{R} \$ 1.000,00$, sendo freqüentemente menor;

- não se dedica ao estudo fora da sala de aula. Não dispõe de tempo para tanto e não desenvolveu disciplina e métodos que lhe permitam fazê-lo, pelo fato de provir de um sistema educacional já marcado pela precariedade nos níveis fundamental e médio;

- a precariedade de sua formação deve-se em grande medida às condições gerais do país, mas especialmente à baixa qualidade da educação fundamental do Brasil. Pesquisas comparativas conduzidas por organismos internacionais indicam que o ensino brasileiro é infelizmente dos menos qualificados do mundo. Quando se mede, por critérios aceitos internacionalmente por pedagogos, o desempenho dos alunos que frequientaram o ensino fundamental em nosso país, não podemos deixar de concluir que boa parte de nossas estatísticas sobre alfabetização deveriam ser revistas, com a inclusão da categoria analfabetos funcionais. Não adentraremos tema tão polêmico como tentar inferir a percentagem de analfabetos funcionais que constam de nossas estatísticas como alfabetizados, mas qualquer professor universitário sabe que sempre há na classe analfabetos funcionais. Alunos que não sabem ler, com imensas dificuldades para entender um texto na 
língua pátria. Não dominam a aritmética e a álgebra básica. Ignoram rudimentos de história e geografia pátrias. Disciplinas que implicam conhecimento de matemática e língua portuguesa são as que mais se ressentem dessas dificuldades;

- é ainda um credencialista que acredita na mágica do diploma como chave que lhe abrirá portas para carreira e futuro melhores. Acredita mais no diploma do que no conhecimento e nos processos educacionais necessários para adquiri-lo. Sua prioridade é diplomar-se. Pouca atenção é dada, por poucos, a educar-se;

- a instituição onde estuda não pratica a reprovação. Esta que era um evento absolutamente ordinário na vida do estudante, hoje, foi eliminada. Reprovar pode até ser visto como prova de ineficácia pedagógica e altos índices de reprovação são indicadores de maus sistemas educacionais. Com o afastamento da reprovação assegura-se a aprovação, desde que o aluno pague suas taxas e compareça às aulas requeridas em regimento. Do ponto de vista da maioria das Instituições de Ensino Superior, a reprovação atrapalha o planejamento acadêmico, o fluxo de caixa e atravanca o uso de instalações.

Para concluir este breve perfil de nosso aluno modal de graduação em administração, matriculado nos dois milhares de cursos existentes, tenta-se inferir qual a sua concepção da profissão de administrador. Estatísticas e classificações de órgãos oficiais apresentam uma longa lista de ocupações como administrativas. Isso eleva o percentual de administradores a algo entre $10 \%$ e $15 \%$ da população economicamente ativa (PEA). Em nosso país isso poderia representar entre 8.200 .000 e 12.300 .000 postos de trabalho ocupados por administradores.

Essas classificações, produzidas por especialistas em economia do trabalho, causam espécie à maioria dos administradores e professores de administração. Na verdade, não podem ser tantos os postos de trabalho para administradores. Isso implica ter uma definição das tarefas do administrador, que serve de base para tal classificação. Para pessoas que olham para a administração como management, segundo a tradição norteamericana, poucos seriam managers. Somente se considerariam aquelas pessoas responsáveis pelo comando de organizações empresarias e que nelas ocupam as posições de cúpula, e de média e, eventualmente, baixa gerência. A maioria das tarefas de supervisão estaria excluída da definição de manager.

$\mathrm{Na}$ administração pública, veremos que cargos de direção são os responsáveis pelas funções propriamente executivas. A maioria das posições de supervisão e chefia de primeira linha, bem como a multidão de escriturários, não são considerados administradores públicos, no sentido que essa palavra tem em diversos países. No Reino Unido, há o senior civil service, e na França, aqueles oriundos das grandes escolas (grandes écoles), especialmente a ENA-Escola Nacional de Administração. Em nosso país, os cargos que podem ser considerados propriamente administrativos, acabam sendo providos em comissão, dadas as peculiaridades do sistema político e da administração pública brasileiros.

A maioria dos matriculados em nossos cursos de graduação não aspira certamente a posições como estas. $\mathrm{O}$ curso de administração se tornou em nosso país a vanguarda da massificação da educação universitária e é procurado por aqueles que desejam ou necessitam de um diploma universitário, sem que tenham um interesse mais genuíno pela profissão de administrador como aqui entendida.

A massificação e o espantoso número de cursos e de matriculados tornaram o Brasil um país com o maior número de cursos de administração no mundo, superando de longe os EUA. Isso tornou o curso de graduação mais um curso de educação geral (general education) do que um curso marcado pelo rigor de conteúdos. Da mesma forma, sua qualidade passou a sofrer com tal expansão, o que se faz sentir tanto pelo alunado -selecionado através de um vestibular classificatório e que não necessariamente seleciona capacitações - como pelo corpo docente. Na verdade, não faz parte do universo mental da maioria dos matriculados que um administrador possa aspirar a uma carreira em que chegue à cúpula de grandes organizações, sejam elas empresas privadas ou estatais, organizações de terceiro setor ou órgãos da administração pública. A grande maioria tem um nível de aspirações compatível com sua extração social e com as reais perspectivas que o país oferece à maioria de seus cidadãos. 


\section{A docência e a lacuna entre a graduação e a pós- graduação}

$\mathrm{O}$ que foi até aqui colocado permite que se vislumbre as transformações pelas quais vem passando o ensino universitário, a universidade e o seu alunado. São propostas, expectativas e aspirações diversas das que por longo tempo moldaram o universo do ensino universitário. A universidade deixou de ser um centro influente, mas pequeno, para se tornar um amplo espaço abrigando uma massa em ascensão, que deseja diplomas e um certo tipo de educação, mas não necessariamente o que a universidade tradicionalmente ofereceu.

Não se pode evitar o percurso de uma universidade oligárquica (para poucos) para uma universidade que deve abrigar muitos, e preferivelmente a totalidade das pessoas em idade de freqüentá-la. A pós-graduação, por suas origens aqui já apresentadas, tende a ser fenômeno de menor porte - em termos de número de docentes e discentes - e sua proposta tende também a um fenômeno oligárquico (para poucos). Certamente, haverá sempre menor número de pessoas atuando no stricto sensu, mas isso não significa que seja de porte reduzido.

Antes do formato atual - estabelecido pelo Parecer nº 965/65 do Conselho Federal de Educação -, o que se tinha como pós-graduação no país era pouco estruturado. Havia os graus de doutor e de livre docente, cuja obtenção, entretanto, fazia-se fundamentalmente pela apresentação de um trabalho inédito. Ao livre docente se solicitava a demonstração de alguma competência docente; ao doutor, apenas uma tese. As pessoas a se doutorarem e obterem a livre docência, já eram acadêmicos, ou seja, já estavam inseridas como docentes e pesquisadores nos quadros da universidade. Doutores e livre docentes eram graus que se obtinham na meia idade, já em situação avançada na carreira e como demonstração de maturidade intelectual e profissional.

O novo formato da pós-graduação, adotado a partir da década de 1970 e vigorosamente sustentado pelo I Programa Nacional de Pós-Graduação (PNPG), acoplava os graus de mestre e doutor ao exercício da docência e à realização de atividades de pesquisa na universidade. Sinalizava também para um processo mais estruturado e, seguramente, com número muito maior de mestres e doutores do que o que existia anteriormente para os graus de doutor e livre docente. Atualmente, é contínua a pressão por um maior número de vagas no stricto sensu, visando garantir qualidade à graduação, a qual passa por uma acelerada expansão. No entanto, dentre os vários obstáculos estão a desproporção entre o número de mestres e doutores que se formam e as necessidades docentes da graduação, a dificuldade em se expandir a pós-graduação sem que seja comprometida sua qualidade.

Não se pode deixar de levar em conta que os critérios de avaliação da Capes reservam os níveis mais elevados apenas a programas que possam ombrear com seus similares internacionais em países de Primeiro Mundo. Além disso, a ênfase do stricto sensu vem sendo mais desenvolver habilidades de pesquisa que resultem em publicações. Poucos programas contêm disciplinas voltadas para a área de pedagogia , como a didática, a psicologia educacional e as tecnologias de instrução.

Como os programas stricto sensu enfatizam a pesquisa e a atualização científica, o que se tem ao final é um profissional bastante distanciado dos problemas da graduação. Isso se refere não somente ao tipo de aluno, como já foi revisto, mas especialmente no que respeita aos conteúdos programáticos da graduação. O universo de preocupações e da vanguarda do conhecimento, as questões candentes (issues) e os dilemas teóricos que constituem o cerne da pós-graduação, não são alimento para um curso de graduação massificado e voltado para um alunado com outra formação, outras expectativas e aspirações.

\section{Redução da lacuna entre pós- graduação e graduação}

Voltar as atenções para as necessidades da graduação deve ser uma preocupação e parte da agenda da pósgraduação. Para que isso se efetive, algumas sugestões são apresentadas em sequiência:

- a primeira é que os programas stricto sensu incluam em seus curricula atividades que visem à formação de professores. Isso não é problemático de ser feito, especialmente, se a pós-graduação dispuser-se a lançar mão das experiências acumuladas em outras áreas, como os diversos programas educacionais. Disciplinas vinculadas ao ensino e ao processo educacional deveriam passar a integrar as grades dos cursos. Dentre 
estas ressaltaríamos noções de didática, fundamentos de filosofia da educação e noções essenciais de psicologia educacional. Na verdade, está a se recomendar que sejam incluídos aqui cursos que há muito integram as exigências para a licenciatura naquelas formações que preparam professores para o ensino fundamental e médio.

- familiarizar o mestrando ou doutorando com modernas tecnologias e experimentos na área de ensino de administração. A preocupação com as necessidades de se alterar métodos de ensino em face do perfil do novo estudante universitário não é um problema apenas brasileiro, mas de todas as sociedades onde o ensino universitário foi massificado. Classes numerosas, a vida quotidiana já permeada por hábitos de lazer envolvendo a televisão e o cinema tornou a leitura menos familiar como fonte de informações e menos praticada pelas novas gerações. Nessa situação, e lidando-se com o alunado de nossos dias, as técnicas tradicionais de preleções, seguidas e precedidas de leituras e interpretação de textos passam a ser pouco eficazes. A maioria dos estudantes nem sequer domina a leitura, pois a maioria das pessoas perdeu esse hábito. Não devemos esquecer de que até duas gerações, a leitura era uma forma de lazer para vastos segmentos sociais, tanto que romances de folhetim foram grandes sucessos;

- atualmente, a experimentação em sala de aula envolve técnicas de experiential learning (ou aprendizado experiencial) e técnicas de educação a distância. Embora hoje em dia haja restrições ao uso da Internet e da televisão como instrumentos de instrução, não há como retroceder. Essas tecnologias estão entre nós e não deixarão de ser utilizadas também na educação. É fato que algumas instituições, especialmente as privadas, têm usado mal esses recursos, visando tão somente à redução de custos e não voltados primordialmente ao aprimoramento dos alunos e da qualidade do ensino;

- as novas tecnologias já promoveram mudanças substancias no papel do professor. Tradicionalmente, este atuava com autonomia absoluta na geração de seu material de ensino, na elaboração de seus programas, na escolha dos métodos de ensino e nos conteúdos. Isso, naturalmente respeitando as imposições legais, como um currículo ou uma grade curricular mínima. Já se pode perceber hoje que, muitas vezes, as atividades de professores envolvem principalmente a preparação de material didático. Os livros de texto produzidos nos últimos anos na área de administração trazem CDs e remetem a sites na Web nos quais uma enorme quantidade de material adicional é encontrada e onde também informações e conteúdos do livro de texto são freqüentemente atualizados. Com o tamanho das classes e a necessária criação de diversas turmas que freqüientam o mesmo curso, ensinado por vários professores, necessidades de uniformização acabam por se impor. Para que tal uniformização ocorra e todos os alunos tenham acesso aos mesmos conteúdos, deve ser produzido material comum a todos. Não se trata apenas de usar o mesmo livro de texto, mas as mesmas transparências ou conjuntos de slides, os mesmo casos e exercícios e os mesmo planos de aula.

- Essa realidade pode obrigar a uma divisão do trabalhão docente com professores voltados exclusivamente à sala de aula, os nossos "dadores de aulas", e os que produzem material para que se ministrem as aulas. Nessa divisão, mestres e doutores, (especialmente os doutores) podem ter um papel de produtores de texto e outras formas de material. Talvez esta seja uma importante contribuição da pós-graduação ao aprimoramento da qualidade da graduação.

- é indispensável que mestrandos e doutorandos adquiram alguma experiência docente como alunos de pósgraduação. A idade dos estudantes de pós-graduação tende a diminuir. Se nos primeiros anos da pósgraduação, os alunos eram freqüentemente professores já experientes, hoje em dia, não é incomum que se ingresse no mestrado imediatamente após a conclusão da graduação, e concluído o mestrado se entre no doutorado. Se atentarmos que é possível o ingresso no doutorado diretamente a partir da graduação, sem que se passe pelo mestrado, então, teremos doutorandos sem experiência profissional - a não ser o estágio necessário para se graduar - nem experiência docente. Essas lacunas não são admissíveis em profissionais do ensino que deverão enfrentar alunos num futuro próximo. Isso implica que durante os cursos de mestrado e doutorado os alunos de pós-graduação sejam obrigados a ensinar. Alguns programas espontaneamente tomaram a iniciativa de criar a figura do assistente de ensino, migração do TA (teaching assistant) norteamericano. A Capes também estimula a prática, mas certamente a importância que a maioria dos programas dá ao treinamento docente de seus alunos é reduzida, muitas vezes, inexistente. As atenções e energias estão voltadas para a pesquisa e para a redação de trabalhos de final de curso, submissão às revistas científicas, a 
encontros diversos e à tese ou dissertação que coroam o curso. Não estamos a afirmar que essas atividades devam ter sua importância reduzida. Reconhecemos que elas constituem o cerne da pós-graduação. Mas que se adicione também a prática do ensino que pode até tornar-se obrigatória;

- a produção de livros de texto pode ser estimulada no âmbito de programas de pós-graduação. Ainda há um percentual elevado de livros de texto traduzidos que são usados em nossos cursos de graduação. É fato que cresce o número de livros produzidos por autores brasileiros. Entretanto, ainda é comum a queixa e a crítica de que nos fazem falta bons livros de texto nacionais, escritos por autores brasileiros e que incorporem a realidade e as experiências de nosso país.

\section{A Associação Nacional de Pós Graduação e Pesquisa em Administração (Anpad) e o Programa de Capacitação de Docentes em Administração (PDCA)}

A história da Anpad confunde-se, em boa medida, com a institucionalização da pós-graduação brasileira a partir da década de 1970. Dessa maneira, a ênfase tendeu a ser a pesquisa e as publicações. No início, a fim de fortalecer programas de pós-graduação que se iniciavam na maioria das Instituições de Ensino Superior, freqüentemente foi dispensado à pós-graduação um tratamento privilegiado, colocando-a num nicho dentro da universidade. Criaram-se coordenações, vice-reitorias e pró-reitorias que deveriam dela se ocupar. No entanto, isso implicava distanciá-la da graduação, especialmente, do ensino da graduação.

A ANPAD realizou desde o início seu Encontro Anual (Enanpad) onde era apresentada a produção científica dos programas associados. Esses encontros, vistos em seu conjunto, até o momento chegaram a 30, têm características heterogêneas. No início, a quantidade e a qualidade dos trabalhos apresentados estavam muito distantes do que hoje temos. Mesmo que atualmente se critique com frequiência a qualidade de nossa produção, especialmente quando se fazem comparações internacionais, não há dúvida de que a trajetória em termos de qualidade é também ascendente. A grande explosão quantitativa se deu a partir dos últimos 10 anos, tornando a Anpad uma das maiores organizações do gênero no mundo, só superada pela Academy of Management. No 30 Enanpad, tivemos mais de 3.000 submissões e aproximadamente 850 trabalhos selecionados para apresentação em suas diversas formas. Tudo isso indica uma associação voltada primordialmente para a pesquisa, a publicação e a difusão da produção científica.

Todavia, não se pode inferir que a Anpad tenha em qualquer momento deixado de lado a preocupação com a docência. Dentre as 10 divisões atualmente abrigadas na associação, uma se ocupa especificamente de ensino. É a Divisão de Ensino e Pesquisa em Administração e Contabilidade (EPQ). Entretanto, há cerca de três anos foi criado um programa, por decisão da assembléia geral, o Programa de Capacitação de Docentes em Administração (PDCA), cujos objetivos são o de fomentar o interesse e a capacitação de mestrandos e doutorandos nos diversos programas associados.

O PCDA é um programa flexível. Não tem nenhuma rigidez em termos de estrutura, conteúdo ou de atividades a serem desenvolvidas. Os programas envolvidos ainda preferem considerar a atividade como um "piloto" e as abordagens variam. Há desde as puramente acadêmicas - o que significa ter uma linha de pesquisa voltada para o ensino, docência e educação em administração - até outras em que as atividades podem se aproximar do treinamento efetivo em técnicas de docência, aproximando-se do mundo de cursos voltados à profissionalização, como o lato sensu e a graduação. Já outros programas pensam em criar em função de linhas de pesquisa, cursos e seminários voltados para problemas de ensino e docência. Dessa maneira, a Anpad resgata uma vocação que sempre esteve presente, mas que por longo tempo permaneceu latente, pela preocupação em consolidar a pesquisa e a publicação.

A capacitação docente tende a ser questão de importância crescente em função da redução na idade e da menor experiência profissional de muitos dos atuais alunos de cursos de mestrado e doutorado. Atualmente, a idade tende a reduzir-se especialmente para os programas de doutorado. Há uma tendência de estagnação relativa dos mestrados acadêmicos e de expansão dos mestrados profissionais. Diante disso, os doutorados sobressaem como o único curso puramente acadêmico no stricto sensu. Isso levará a que a se saia da graduação diretamente para o doutorado. O resultado serão classes de doutorandos bem mais jovens do que as atuais. Essa diferença 
será ainda mais acentuada numa comparação com as classes do passado, formadas por pessoas já envolvidas na vida acadêmica, que lecionavam há anos e, portanto, eram mais experientes. Os doutorandos virão diretamente da graduação sem que tenham ensinado, e mesmo aqueles que já o tenham feito terão pouca experiência.

O objetivo do PCDA é formar doutores e mestres que também tenham um dimensão educacional do programa e não o entendam apenas como um importante passo em sua formação de pesquisadores e produtores científicos autônomos. A tarefa é árdua e extensa. Atualmente, temos no país aproximadamente 600.000 matrículas na graduação em administração e mais de 2.000 cursos, envolvendo cerca de 36.000 professores. Na pós-graduação atuam aproximadamente 600 professores, todos eles com titulação mínima de doutorado e alguns com pós- doutorado. Há muito por fazer e não é tarefa para apenas uma geração.

O que se pretende com o PCDA é qualificar mestres e doutores, já capacitados como pesquisadores, para que entrem em sala de aula seguros e preparados. Que esses mestres e doutores não apenas transmitam a um alunado recém-chegado à universidade o que apreenderam na pós-graduação, mas também o que tiveram a oportunidade de descobrir em seus trabalhos autônomos de pesquisadores. 


\section{Leituras sugeridas}

BERTERO, C. O. Ensino e pesquisa em administração. São Paulo: Thomson, 2006.

CARVALHO NETO, S.; ZWICKER, R.; CAM PANHOL, E. M. Ensino on-line na graduação de administração: um estudo de prós, contras e da possibilidade de implantação de um ambiente virtual de aprendizagem em uma IES do estado de São Paulo. In: ENANPAD, 30. Anais... Rio de Janeiro: Enanpad, 2006.

COSTA, F. J.; MOREIRA, J. A.; ETHUR, S. Z. 0 perfil dos professores de pós-graduação em administração na perspectiva dos alunos. In: ENANPAD, 30. Anais... Rio de Janeiro: Enanpad, 2006.

EBOLI, M. Educação corporativa no Brasil - mitos e verdades. São Paulo: Gente, 2004.

GORDON, R. A.; HOWLL, J.E. Higher education of business. New York: Columbia University Press, 1959.

MINTZBERG, H. M BA? Não, obrigado - uma visão crítica sobre a gestão e o desenvolvimento de gerentes. Porto Alegre: Bookman, 2006.

NUNES, S. C.; BARBOSA, A. C. Q. Pedagogia das competências: realidade no ensino em administração? In: ENANPAD, 30. Anais... Rio de J aneiro: Enanpad, 2006.

PFEFFER, J.; FONG, C. T. The end of business schools? Less success than meets the eye. Academy of Management Learning and Education, v.1, n.1, p.78-95., 2002.

ROSAS, A. R.; AZUAYA, A. C. A. Jogos de empresas na educação superior no Brasil: perspectivas para 2010. In: ENANPAD, 30. Anais... Rio de Janeiro: Enanpad, 2006.

SILVA, W. R.; MACHADO, M. A. V. M otivos que levam os alunos a cursar graduação em administração: um estudo nas instituições públicas e privadas do estado da Paraíba. In: ENANPAD, 30. Anais... Rio de Janeiro: Enanpad, 2006. 